\title{
Formação de professores alfabetizadores pelo Programa Pacto Nacional de Alfabetização na Idade Certa: reflexões sobre avaliação realizada por municípios
}

\author{
Leonete Luzia Schmidt ${ }^{1}$ \\ Jacqueline de Souza ${ }^{2}$
}

\begin{abstract}
RESUMO
O objetivo do presente artigo é conhecer como os municípios avaliaram a implementação e realização da formação continuada de professores no PNAIC. Para tanto foi necessário verificar quem era responsável pelo acompanhamento das ações do Pacto no município; identificar como era realizada a avaliação desse programa; e analisar a relação entre o que consta na proposta do Pacto e a avaliação realizada pelos municípios. Teve como procedimento metodológico a pesquisa documental e de campo, esta última realizada na Associação dos Municípios da Região de Laguna (AMUREL). Os resultados mostraram que os municípios assinaram o Pacto e designaram coordenação local e orientadores de estudos, sendo estes os responsáveis pela avaliação, e consideraram que a formação fora exitosa. No entanto, não foi constatado movimento por parte dos municípios no sentido de fazer com que a proposta de alfabetização trabalhada na formação fosse transformada em política pública de alfabetização nos municípios.
\end{abstract}

PALAVRAS-CHAVE: Formação Continuada de Professores. Avaliação. Alfabetização. PNAIC.

\footnotetext{
${ }^{1}$ Pós-Doutorado em Educação. Universidade do Sul de Santa Catarina - Unisul, Tubarão, Santa Catarina, Brasil. https://orcid.org/0000-0002-3239-2980.leonetes@gmail.com.

2 Mestre em Educação. Universidade do Sul de Santa Catarina - Unisul, Tubarão, Santa Catarina, Brasil. https://orcid.org/0000-0003-1598-5933.profjacquesouza@gmail.com.
} 
Literacy Teacher Training by the Right-Age National Literacy Pact Program (PNAIC): Reflections on Evaluation Carried out by the Municipalities

\begin{abstract}
The aim of this article is to know how the municipalities evaluated the implementation of continuing teacher education at PNAIC. For that purpose, it was necessary to verify who was responsible for monitoring the Pact's actions in the municipality; to identify how the evaluation of this program was performed; and to analyze the relationship between what is contained in the proposal of the Pact and the evaluation carried out by the municipalities. The methodological procedure was the documentary and field research, the latter carried out at the Association of Municipalities of Laguna Region (AMUREL). The results showed that the municipalities signed the Pact and designated local coordination and study advisors, who were held responsible for the evaluation, and considered that the training was successful. However, the research revealed that the municipalities did not make any effort for the proposal of literacy that was worked in training to be transformed into public policy for literacy in the municipalities.
\end{abstract}

KEYWORDS: Continuing teacher training. Evaluation. Literacy Education. PNAIC.

Formación de Profesores de Alfabetización por el Programa Pacto Nacional de Alfabetización en la Edad Correcta (PNAIC): Reflexiones sobre la Evaluación Realizada por Municipios

\title{
RESUMEN
}

El objetivo de este artículo es saber cómo los municipios evaluaron la implementación y la realización de la formación continua de docentes en PNAIC. Para ello, fue necesario verificar quién era el responsable de monitorear las acciones del Pacto en el municipio; identificar cómo se realizó la evaluación de ese programa; y analizar la relación entre el contenido de la propuesta del Pacto y la evaluación realizada por los municipios. El procedimiento metodológico fue la investigación documental y de campo, esta última realizada en la Asociación de 


\begin{abstract}
Municipios de la Región de Laguna (AMUREL). Los resultados mostraron que los municipios firmaron el Pacto y designaron coordinación local y orientadores de estudios, quienes fueron los responsables de la evaluación, y consideraron que la capacitación fue exitosa. Sin embargo, se constató que los municipios no hicieron movimiento para que la propuesta de alfabetización trabajada en la capacitación se transformara en una política pública de alfabetización en los municipios.
\end{abstract}

PALABRAS CLAVE: Formación continuada de profesores. Evaluación.

Alfabetización. PNAIC.

$$
* * *
$$

\title{
Introdução
}

Dentre as políticas públicas de formação continuada de professores nas últimas décadas está a do Pacto Nacional da Alfabetização na Idade Certa (PNAIC). Neste, os governos federal, do Distrito Federal, dos estados e municípios assumem um compromisso formal de assegurar que todas as crianças estejam alfabetizadas até os oito de idade. Além disso atribuem a formação dos professores alfabetizadores grande peso para assegurar que este compromisso se concretize. Trata-se de uma política de formação do professor vinculada às reformas do Estado realizadas a partir de 1990, quando o Brasil assumiu, na Conferência Mundial de Educação para Todos ${ }^{3}$, o compromisso de erradicar o analfabetismo no país.

Dentre as inúmeras reformas realizadas pelo Estado brasileiro na educação está a ampliação do Ensino Fundamental de oito para nove anos de duração, com definição dos três primeiros anos para a alfabetização, através da Lei n ${ }^{\circ}$ 11.274/06 (BRASIL, 2006). A partir desta lei, um conjunto

\footnotetext{
${ }^{3}$ A Conferência Mundial de Educação Para Todos foi realizada na Tailândia, em 1990, é considerada o grande marco da reforma educacional empreendida a partir desse período. Organizada pela Organização das Nações Unidas para a Educação, a Ciência e a Cultura (UNESCO), Fundo das Nações Unidas para a Infância (UNICEF), Programa das Nações Unidas para o Desenvolvimento (PNUD) e Banco Mundial, e subscrita por 155 governos que assumiram o compromisso de assegurar uma Educação Básica de qualidade a crianças, jovens e adultos, resultou em consensos que deveriam penetrar a formulação dos planos decenais de educação, em especial nos países mais populosos e com os maiores índices de analfabetismo do mundo (SHIROMA; MORAES; EVANGELISTA, 2002).
} 
de outras medidas legais foi emitida pelo Estado, objetivando assegurar que todas as crianças aprendam a ler, escrever e calcular até os oito anos de idade.

Esta definição de alfabetização até os oito anos de idade também consta no Plano Nacional de Educação (PNE) para o decênio 2014/2024 (PNE - 2014/2014), que tem como diretrizes a erradicação do analfabetismo e a melhoria da qualidade da educação, dentre outras, propondo, na Meta 5, "alfabetizar todas as crianças até, no máximo, os oito anos de idade" (BRASIL, 2015).

Seguindo o modelo de multiplicadores ${ }^{4}$, a formação proposta no PNAIC, contempla professores alfabetizadores dos três primeiros anos do Ensino Fundamental e coordenadores pedagógicos vinculados às classes de alfabetização, conforme consta no artigo $7^{\circ}$ da Portaria $n^{\circ} 867$, de 4 de julho de 2012 .

Um programa criado pelo Governo Federal para ser desenvolvido em parceria com estados e municípios pressupõe que estes entes da federação acompanharam sua realização e os resultados alcançados. Além disso, nos cadernos do PNAIC a avaliação do programa de formação é uma das ações a serem realizadas. Neste sentido, realizou-se um levantamento junto a municípios da Associação dos Municípios da Região de Laguna (AMUREL) ${ }^{5}$, sul do estado de Santa Catarina, sobre como foi realizado este processo de avaliação do programa de formação de professores em âmbito municipal.

A pesquisa foi realizada em cinco municípios: um deles de grande porte, dois de médio e dois de pequeno porte. Foram feitas entrevistas com os orientadores de estudo, coordenador local e secretária de Educação. Ao todo foram oito orientadores de estudo, sendo três do município 1; um orientador de estudos do município 2, dois orientadores de estudos do município 3; um orientador de estudos do município 4; um orientador de

\footnotetext{
${ }^{4}$ Seguindo o conceito trazido por Freitas (2002), multiplicadores seriam professores que passavam por processos de formação e se transformavam em formadores de professores e, assim, sucessivamente, em uma cadeia de formação.

${ }^{5}$ A AMUREL é uma entidade com personalidade jurídica própria de direito privado, de duração indeterminada e sem fins lucrativos, visando à interação administrativa, econômica e social dos municípios que a compõem, regendo-se pelo seu Estatuto (Mais informações em <amurel.org.br>).
} 
estudos do município 5; também uma secretária municipal e a coordenadora local deste município, no período de 2013 a 2016.

Além da entrevista foram analisados os seguintes documentos: portaria que cria o PNAIC; termo de adesão; caderno de apresentação do Pacto, que contém orientações sobre a formação de professores alfabetizadores; documento orientador das ações de formação e demais cadernos e/ou orientação do Ministério da Educação (MEC) sobre a formação de professores alfabetizadores; relatórios de acompanhamento de professores realizados pelos coordenadores e orientadores de estudos; e material de professores que foram publicados. Os resultados estão organizados em quatro itens: a formação continuada de professores no PNAIC; o envolvimento dos municípios com a formação dos professores alfabetizadores no PNAIC; a avaliação da formação dos professores alfabetizadores no PNAIC pelos municípios; e sistema integrado de monitoramento execução e controle como acompanhamento da formação do professor alfabetizador no PNAIC.

\section{A formação de professores no Pacto Nacional pela Alfabetização na Idade Certa}

O PNAIC foi, inicialmente, uma proposta de formação apresentada pelo Centro de Estudos em Educação e Linguagem da Universidade Federal de Pernambuco (CEEL/UFPE) para atender todos os estados do Nordeste e da Região Norte, articulados com as universidades em que professores tivessem participado do Pró-Letramento.

A partir desse projeto inicial, o MEC adotou o Pacto como política oficial para todo o país e atribuiu às universidades públicas brasileiras a coordenação-geral do Programa, inicialmente previsto para dois anos, contando com coordenação-geral nos estados, professores formadores ligados às universidades, orientadores de estudo provenientes de todos os 
municípios, coordenadores locais dos municípios e professores alfabetizadores.

No final do segundo semestre de 2012, as universidades começaram a constituir as equipes que iriam atuar na formação dos mais de cinco mil municípios que aderiram às ações do PNAIC, e, em 2013, iniciaram a implantação do projeto em âmbito nacional (BRASIL, 2012).

Segundo consta no caderno de apresentação, o PNAIC foi o maior programa de formação de professores já desenvolvido pelo MEC, e visava a garantir o direito de alfabetização a todas as crianças até o final do $3^{\circ}$ ano do Ensino Fundamental. Para que esta ação se efetivasse seria necessário ter como foco a base do processo, ou seja, o aperfeiçoamento do professor alfabetizador. Este eixo $\mathrm{n}^{0} 1$ do Pacto, denominado "formação continuada presencial para professores alfabetizadores e seus orientadores de estudo", está articulado aos demais eixos que compõem o programa, sendo eles: "2. materiais didáticos, obras literárias, obras de apoio pedagógico, jogos e tecnologias educacionais; 3. avaliações sistemáticas; 4. gestão, controle social e mobilização" [...] (BRASIL, 2014a).

Percebe-se que se trata de um programa amplo, incluindo um conjunto de ações articuladas, cuja materialização demanda investimento financeiro e de recursos humanos significativos para viabilizar a qualidade definida na proposta, cujo resultado é a alfabetização com letramento das crianças até o final do $3^{\circ}$ ano do Ensino Fundamental.

O programa de formação continuada tem como pressuposto teóricometodológico a alfabetização na perspectiva do letramento, envolvendo questões pedagógicas e encaminhamentos metodológicos para o Ciclo de Alfabetização. Nesta perspectiva, a apropriação do código deve ser articulada ao contexto e às práticas sociais. Para viabilizar este processo, os materiais pedagógicos e demais itens previstos no eixo 2 eram disponibilizados para a formação, assim como as avaliações sistemáticas que compõem o $3^{\circ}$ eixo eram parte do curso de formação, incluindo, nesse processo, a aplicação de uma avaliação com as crianças do $3^{\circ}$ ano e a 
aplicação de uma avaliação externa universal, elaborada pelo Instituto Nacional de Estudos e Pesquisas Educacionais Anísio Teixeira (INEP), visando a aferir o nível de alfabetização alcançado ao final do ciclo.

A justificativa para a inclusão da avaliação como parte da formação do professor alfabetizador objetivava contribuir com as redes na implementação de medidas e políticas para melhorar os índices de alfabetização. Da mesma forma, o $4^{\circ}$ eixo, referente à gestão, ao controle social e à mobilização, era parte da formação. Este último visava ao fortalecimento do comitê gestor nacional, estadual e municipal, bem como de suas coordenações e a consolidação das articulações entre o MEC e os entes federados de modo a garantir o funcionamento do programa, bem como sua organização, assegurando a qualidade no alcance dos objetivos propostos (BRASIL, 2014).

No entanto, faz-se necessário, também, articular as políticas voltadas à alfabetização no Brasil, ao consenso de políticas neoliberais materializadas em documentos internacionais, conferências e eventos mundiais organizados e/ou mediadas por organismos e organizações internacionais a partir de 1990. Dentre eles, destacam-se: o Ano Internacional da Alfabetização (1990); Declaração Mundial sobre Educação para Todos: satisfação das necessidades básicas de aprendizagem, Jomtien (1990); Declaração de Dakar: Educação Para Todos (2000); Objetivos de Desenvolvimento do Milênio (ODM) (2000); Década das Nações Unidas para a Alfabetização (2003- 2012); Alfabetização para o Empoderamento (Life) (2005); e o Desafio da Alfabetização Global: um perfil da alfabetização de jovens e adultos na metade da Década das Nações Unidas para a Alfabetização 2003-2012. Nesses, o Estado brasileiro assumiu compromissos de diminuir os índices de analfabetismo no país, assim como de ampliar o tempo de permanência das crianças e dos adolescentes na escola, e maiores índices de aprovação.

Articuladas a estes compromissos assumidos pelo Estado brasileiro é que políticas públicas que assegurassem acesso e permanência das crianças na escola foram delineadas. Considerando que as questões de acesso a partir 
da virada do milênio estavam asseguradas, a permanência da criança na escola requer, também, inclusão de questões didático-pedagógicas. A formação continuada dos professores alfabetizadores, proposta no PNAIC, deixa claro que o objetivo não é a reprodução de métodos e técnicas, mas a prática da reflexão da ação pedagógica realizada pelo professor alfabetizador com vistas à reelaboração deste fazer para a melhoria da sua atuação e dos resultados da aprendizagem das crianças.

Considerando a perspectiva teórica anunciada e, ao mesmo tempo, que se trata de uma formação que perdurou por mais de quatro anos, podese dizer que vai ao encontro do entendimento de Libâneo (2004), quando diz que a formação continuada é condição para a aprendizagem permanente dos professores, e a reflexão sobre a prática pedagógica, em uma perspectiva teórica de emancipação crítica dos alunos, terá como consequência a melhoria da qualidade da aprendizagem na escola pública.

As atribuições de cada um dos participantes da Formação Continuada de Professores Alfabetizadores, estão definidas na Resolução $n^{\circ} 4 / 13$, a qual assegura às universidades públicas o papel de coordenação-geral e coordenação-adjunta. Em âmbito municipal havia o coordenador local e o orientador de estudos; o primeiro, responsável por toda a logística da formação no município/estado, pelo cumprimento da carga horária entre os orientadores de estudo e professores alfabetizadores, pelo acompanhamento da aplicação das Provas Brasil 6 e Avaliação Nacional de Alfabetização (ANA) ${ }^{7}$, pelo gerenciamento das senhas do orientador de estudos e dos professores alfabetizadores (BRASIL, 2014). E os orientadores de estudos, como o próprio nome indica, atuavam diretamente com o professor alfabetizador na orientação dos estudos definidos nos cursos de formação nos polos regionais.

\footnotetext{
${ }^{6}$ Prova Brasil é uma avaliação para diagnóstico, em larga escala, desenvolvida pelo INEP/MEC, cujo objetivo é avaliar a qualidade do ensino oferecido pelo sistema educacional brasileiro a partir de testes padronizados.

${ }^{7}$ ANA é uma avaliação externa que objetiva aferir os níveis de alfabetização e letramento em Língua Portuguesa (leitura e escrita) e Matemática dos estudantes do $3^{\circ}$ ano do Ensino Fundamental das escolas públicas. As provas aplicadas aos alunos fornecem três resultados: desempenho em leitura, desempenho em Matemática e desempenho em escrita.
} 
O envolvimento de universidades, poder público de todos os entes federados, escolas de educação básica e professores que atuam em sala de aula é uma questão de grande relevância desse programa de formação de professores. Unir quem produz conhecimento a quem o coloca em prática, viabilizados pelo Estado, é, sem dúvida, aspecto a ser considerado.

Se por um lado há, nesse programa de formação de professores do PNAIC, a questão relevante que é a articulação entre universidade e educação básica, por outro lado, essa formação segue o modelo de multiplicadores, o que nem sempre assegura a qualidade prevista. No caso do PNAIC, a formação dos alfabetizadores era conduzida pelos orientadores de estudo. Estes participavam dos cursos realizados nos polos regionais, cuja formação era conduzida pelos coordenadores-adjuntos das universidades. Nesse processo, as formas de incorporação dos conhecimentos são diferentes de acordo com a formação e conhecimentos de cada um, o que pode levar à fragilização da formação.

Após formação nos polos regionais, no retorno para seus respectivos municípios, os orientadores de estudos reproduziam nos cursos ou reuniões de estudo o que haviam aprendido: leituras, conteúdos e metodologias, dinâmicas/estratégias didáticas, enfim, todo o conhecimento adquirido de modo que os professores fossem agregando novas possibilidades pedagógicas para suas aulas.

Essa proposta de formação, como parte do Pacto, deveria ser efetivada no município em que o professor alfabetizador residia, o que fazia com que a formação ocorresse no local de trabalho do professor ou em escola próxima, o que facilitava sua participação.

\section{O envolvimento dos municípios com a formação dos professores alfabetizadores no PNAIC}

O PNAIC, como já mencionado no item anterior, é resultado de um compromisso formal e solidário assumido pelos governos federal, do Distrito 
Federal, dos estados e dos municípios, desde 2012, para, entre outros compromissos, atender à Meta 5 do PNE, que estabelece a obrigatoriedade de "alfabetizar todas as crianças, no máximo, até o final do $3^{\circ}$ (terceiro) ano do ensino fundamental" (BRASIL, 2015).

De acordo com as informações levantadas junto à AMUREL, os dezoito municípios desta região assinaram o Pacto. Após assinatura, cada município designou coordenadores locais e orientadores de estudos para dar início ao trabalho de formação.

Nas entrevistas pode-se constatar que os municípios designaram responsáveis pela coordenação local e orientação de estudos.

Uma das orientadoras de estudo diz: “[...] eu era a responsável como coordenadora local e a [...] era a orientadora de estudos [...]” (M2-E28. Entrevista realizada em 30/06/2018). Outra entrevistada também confirmou: "[...] Havia... havia... o coordenador, havia as orientadoras $e$, mesmo assim, o secretário da educação também tava por dentro do que nós fazíamos na época” [sic] (M1-E3-Entrevista realizada em 10/01/2018).

$\mathrm{O}$ que nem todos os municípios fizeram foi seguir as determinações presentes nas orientações do Pacto, as quais determinavam que os profissionais que fossem assumir as funções de coordenador e orientador de estudos

deveriam ser escolhidos em processo de seleção pública e transparente, livre de interferências indevidas, relacionadas seja a laços de parentesco, seja a proximidade pessoal, respeitando-se estritamente os pré-requisitos estabelecidos para a função quanto à formação e à experiência exigidas, sendo selecionados entre os profissionais que atendessem aos seguintes requisitos cumulativos: Ser professor efetivo da rede pública de ensino que promove a seleção; ter sido tutor do Programa Pró-Letramento ou ter participado do PNAIC nos anos anteriores; ter disponibilidade

\footnotetext{
${ }^{8}$ Os municípios participantes da pesquisa foram identificados como M1 para município 1; M2 para município 2, M3, para município 3 e assim sucessivamente. Os coordenadores locais e orientadores de estudo de cada município foram identificados como E1, E2, E3.
} 
para dedicar-se ao curso e à multiplicação junto aos professores alfabetizadores (BRASIL, 2015, p. 4).

Considerando informações extraídas das entrevistas com os orientadores de estudo e coordenador local, nem todos os critérios acima descritos foram atendidos pelos municípios ou estado de Santa Catarina, haja vista que a maioria havia sido indicada pela Secretaria de Educação do município e não por processo de seleção pública e transparente.

Constatou-se, junto aos entrevistados, que a formação fora importante para novos aprendizados. Uma das orientadoras falou com grande entusiasmo das atividades realizadas pelas professoras cursistas: "[...] $a$ gente ensinou como fazer a sequência didática, e elas tinham que adequar a cada realidade da sala de aula delas Era bem interessante, porque elas... nossa... ousavam muito, eram muitas atividades maravilhosas e elas registravam em fotos, em vídeos. Nossa! E também as formações... fizeram com que os professores... é... lessem bastante, porque nós, na nossa prática, no nosso dia a dia, a gente não tira tempo pra ler... e a formação fazia, não obrigava, mas fazia com que o professor... lesse, porque se o professor não lesse, ele não saberia, é... fazer... os relatórios. Elas traziam, também, as atividades que elas faziam com os alunos, porque a sequência didática, ela começa... ela começa da leitura e passa por todas as matérias, então, vai Lingua Portuguesa, Ciências, Matemática, mas com foco na Língua Portuguesa, e no final elas traziam trabalhos das crianças, era exposto, era bem legal, era bem legal. Tinha essa... essa... essa interação entre um... uma escola e outra. Então, às vezes, o trabalho da escola X era totalmente diferente da escola $Y$, o [...], que já fica no interior, trazia o trabalho, já era totalmente diferente do pessoal aqui do bairro tal, que é... a escola do centro da cidade, e era, às vezes, o mesmo tema, às vezes lia o mesmo livro e... tinha atividades totalmente diferentes, era bem... bem interessante [...]”. [sic] (M1-E2-Entrevista realizada em 10/01/2018). 
Durante as entrevistas os(as) orientadores(as) de estudo evidenciavam comprometimento com a formação dos professores alfabetizadores que estavam sob sua responsabilidade. Percebeu-se sua satisfação ao afirmar sobre a grande mudança que havia acontecido na forma de as professoras de seu município ministrar suas aulas. Segundo eles(as), favoreceu a prática da escrita e da leitura, haja vista ser necessário realizar uma análise do processo de ensinar e das atividades propostas, consolidando, assim, a prática da reflexão sobre as possíveis formas de materializar as ações aprendidas nas formações. Conforme Hobold e Silva (2014, p. 7),

os formadores de professores precisam oportunizar o desenvolvimento de novos conhecimentos, para que auxiliem na formação de professores críticos e reflexivos sobre as suas ações e responsabilidades perante os desafios de ensinar cidadãos também desenvolvidos em sua criticidade e conscientes da sua cidadania.

A considerar as falas das orientadoras de estudo, a formação oferecida pelo PNAIC seguiu esta direção: a prática cotidiana do professor alfabetizador como ponto de partida para uma nova compreensão dessa mesma prática, a formação continuada como elemento mediador.

No que diz respeito ao acompanhamento/avaliação pelos municípios da formação de professores no PNAIC, o processo foi acompanhado pelos coordenadores locais e orientadores de estudo.

Isso fica evidente quando perguntado para as orientadoras de estudo como era realizado o acompanhamento/avaliação das formações dos professores que participavam do Programa PNAIC, cujas respostas descrevem, regra geral, ações de orientadores e coordenadores locais. Para esta ação utilizavam o acompanhamento em sala de aula para verificar como estavam fazendo com o que aprenderam no curso, relatórios de frequência, diário de bordo. 
Os entrevistados do município 1 responderam que, algumas vezes, faziam visitas às escolas para realizar o acompanhamento das professoras. “[...] e nós íamos, de vez em quando nas salas, pra ver como estava acompanhando a alfabetização, nós fazíamos o acompanhamento através de visitas, né... a gente visitava as escolas, e... era esse o acompanhamento [...]" [sic]. (M1-E2-Entrevista realizada em 10/01/2018). Neste município, podiam sempre contar com a presença da coordenadora de estudos: "[...] Então, a coordenadora estava sempre conosco nas formações noturnas... sempre estava conosco, e... nós íamos para as salas de aula, então, assim: o que acontecia? A gente fazia a formação, passava a parte teórica 'pros' professores [...]” [sic] (M1-E1-Entrevista realizada em 10/01/2018).

Os entrevistados do município 2 fizeram referência ao relatório de frequência como um dos critérios utilizados para a validação da bolsa de estudos. Existia, segundo os relatos, um documento intitulado diário de bordo $^{9}$, no qual as professoras traziam suas principais conclusões e apresentavam um pequeno relato sobre o encontro de formação que havia acontecido: "[...] Com relação ao acompanhamento das formações, eram realizadas através dos registros de frequência e também por registros descritivos de um diário de bordo [...]” (M2-E3 - Entrevista realizada em 30/06/2018).

Os encontros de formação continuada do PNAIC, nos municípios, aconteciam quinzenalmente. Nesta formação, as professoras alfabetizadoras, além dos estudos programados, apresentavam suas dúvidas ou qualquer dificuldade referente à prática pedagógica que vinham realizando para colocar em prática o que trabalhavam nos encontros. A orientadora de estudos, após analisá-las, montava estratégias para trabalhá-las de modo que facilitasse ou sanasse o problema apresentado pela professora. “[...] Depois dos treinamentos nós organizávamos, juntamente com a coordenação, né, através dos planejamentos que a gente

\footnotetext{
9 O diário de bordo trazia as atividades realizadas, registradas diariamente em um caderno, com um breve resumo do encontro.
} 
fazia, e a gente montava os cronogramas do curso e montava as formações, né, os grupos de professores, com as escolas da GERED, né, dando preferência pros professores de primeiro ao terceiro ano. $E$ os encontros aconteciam quinzenalmente, né, presenciais, porque a gente tinha uma parte, também, que a gente fazia a distância” [sic] (M3-E1- Entrevista realizada em 08/10/2018).

Nas falas acima, pode-se perceber que o acompanhamento da formação dos professores alfabetizadores no PNAIC acontecia em visitas das orientadoras de estudos às salas das professoras cursistas, na socialização com explanação e amostra de trabalhos que haviam sido realizados em sala, no acompanhamento dos relatórios de frequência e anotações das práticas em diários e na atenção às professoras que apresentavam dificuldades para realizar a prática pedagógica que havia sido trabalhada nos encontros de formação. Ou seja, o acompanhamento se dava pelos orientadores de estudos e/ou coordenadores locais referente ao que registravam sobre o seu fazer pedagógico.

Saviani (2001 apud SALOMÃO, 2014, p. 60) enfatiza que:

A formação continuada não deve se restringir à resolução de problemas específicos de sala de aula, mas contribuir para que o professor ultrapasse a visão compartimentada da atividade escolar e passe a analisar os acontecimentos sociais, contribuindo para sua transformação.

Neste sentido, conforme o autor, a formação continuada de professores alfabetizadores torna-se o estudo teórico de temas definidos nos materiais impressos, centrando-se na realização de atividades em sala de aula, constituindo-se mais como estratégia na construção de novos conhecimentos, a partir da prática social, compreendendo esta dinâmica social de forma articulada com o contexto social mais amplo (SALOMÃO, 2014). 
Para Alferes e Mainardes (2019, p. 48),

os orientadores de estudo e professores alfabetizadores interpretam, e traduzem em ação, os textos do PNAIC de formas diferenciadas. Ainda, com base em aspectos da teoria de Bernstein, argumenta-se que o PNAIC apresenta elementos da chamada pedagogia mista, ou seja, fundamenta-se no modelo pedagógico de competência e, também, em alguns aspectos do modelo pedagógico de desempenho. Por um lado, o Pacto enfatiza o emprego de práticas sistemáticas no processo de alfabetização e monitoramento da aprendizagem dos alunos (o que está relacionado ao modelo de competência). Por outro lado, há preocupação com a melhoria de índices e desenvolvimento de estratégias de avaliação externa (modelo pedagógico de desempenho).

Ainda que o Pacto tenha se constituído em um programa inovador e necessário para a melhoria da qualidade da aprendizagem no Ciclo de Alfabetização, além, claro, do favorecimento na busca de caminhos que fizessem os professores reverem e ressignificarem sua forma de atuar em sala de aula, não deixa, também, de estar focado no desenvolvimento de competências e desempenho dos estudantes (ALFERES; MAINARDES, 2019).

\section{A avaliação da formação dos professores alfabetizadores no PNAIC pelos municípios}

Coordenadores e orientadores de estudos foram questionados sobre como foram realizadas as avaliações de aprendizagem pela rede municipal ou estadual, durante o período de vigência do PNAIC, mais especificamente de 2013 a 2016.

Neste questionamento, o objetivo era perceber se as redes de ensino utilizaram outras formas de avaliar a formação que acontecia em seu 
município, tentando identificar os impactos que este aprendizado teria na vida escolar dos alunos e dos professores.

As entrevistadas deixaram claro que não foram realizadas avaliações pelas redes de ensino, ou uma prova para verificar mudanças na aprendizagem das crianças depois do início do PNAIC. Entretanto, fizeram referência às avaliações em larga escala, aos relatórios trazidos pelas professoras e socializados nos encontros de formação, e aos acompanhamentos na sala de aula, o que não deixam de ser avaliações realizadas.

“[...] Não teve nenhuma avaliação extra, somente a ANA [...] a única coisa que teve foi uma avaliação 2014, 2015, no programa do SIMEC [Sistema Integrado de Monitoramento, Execução e Controle], para avaliar a aplicabilidade do Pacto na prática pedagógica do professor. Então, o professor, ele postava as fotos, ele fazia uma prova objetiva, também, sobre a metodologia! [...]” [sic] (M3-E2-Entrevista realizada em 22/10/2018).

Outra entrevistada falou: “[...] A nossa avaliação era através de... de relatório. A... rede, ela não montou nenhuma prova, nada pras crianças, tá? Os orientadores... alfabetizadores faziam um relatório mensal e davam um retorno [...] A gente fazia a provinha Ana. [...] o município não fez nada, não elaborou nenhum tipo de prova específica... pra avaliação [...]” [sic] (M4-E1Entrevista realizada em 26/10/2018).

Pode-se perceber que as avaliações estavam sendo realizadas, tanto para aferir o rendimento das crianças com a realização da ANA quanto dos professores cursistas com os relatórios a serem inseridos no SIMEC.

Estes relatórios foram citados nas entrevistas e apresentados como dois modelos que deveriam ser seguidos: um relatório sucinto e um relatório completo, os quais tanto as professoras como as orientadoras de estudo tinham que realizar. Estes relatórios continham um cabeçalho com identificação do município, nome do coordenador local, do orientador de estudos, o período dos encontros relatados e uma breve descrição do encontro de formação no município. O relatório sucinto, como o próprio nome 
indica, não continha detalhes da formação, já o relatório completo, continha detalhadamente o que fora realizado na formação.

Considerando que a maioria dos entrevistados mencionou que as avaliações do PNAIC nos municípios foram realizadas através desses relatórios dos professores alfabetizadores, buscou-se conhecer o conteúdo deles. O entrevistado do M1 informou que eram dois modelos, um sucinto e outro completo: “[...] Então, a gente seguiu um padrão, enquanto teve bolsa, a gente seguiu um relatório padrão... mês, um relatório sucinto e um completo. No relatório sucinto, elas... é... de uma... forma breve, explicasse o que foi trabalhado à noite, e como elas aplicariam na sala de aula, de uma forma breve. Então, esse completo, às vezes, demorava 45 dias pra ser entregue... a gente aceitava algumas coisas, tipo... todas as turmas de primeiro ano faziam o mesmo projeto, então elas montavam a mesma estrutura $e$ anexavam partes separadas... dai o relatório completo, ele era um pouco mais maleável [...]. Orientadores de estudo realizavam relatórios para entregar ao coordenador local e, posteriormente, ao formador do polo" [sic] (M1-E1Entrevista realizada em 10/01/2018). As formadoras das orientadoras, após a leitura do relatório que era enviado via e-mail, como realização de suas tarefas, retornavam enviando um relatório com um parecer pontuando suas considerações acerca do que elas haviam desenvolvido no período estabelecido.

O percurso do desenvolvimento do projeto, ou no caso, do programa de formação continuada deveria ter como foco a verificação diagnóstica de quais etapas estão sendo cumpridas e quais precisam ser revistas.

Se as redes não contavam com avaliações de acompanhamento da formação, o MEC acompanhava a formação dos professores pelo PNAIC por meio do SIMEC.

\section{Sistema Integrado de Monitoramento Execução e Controle como acompanhamento da formação do professor alfabetizador no PNAIC}


O SIMEC é um portal operacional e de gestão do MEC que trata do orçamento e monitoramento das propostas on-line do Governo Federal na área da educação. É no SIMEC que os gestores verificam o andamento dos Planos de Ações Articuladas em suas cidades (BRASIL, 2018).

No manual de orientações para preenchimento do sistema consta uma breve descrição da forma de avaliação presente no sistema on-line:

Coordenador da IES: cadastra a equipe da IES, forma as turmas de Orientadores de Estudo e avalia o Coordenador Adjunto; Coordenador Adjunto da IES: avalia os Supervisores; Supervisor: avalia os Formadores; Formador: avalia os Orientadores de Estudo; Coordenador local: em conjunto com os Formadores, avalia os Orientadores de Estudo; Orientadores de Estudo: avalia os Professores Alfabetizadores e pode ser solicitado a avaliar o seu Formador e Coordenador Local.; Professor Alfabetizador: realiza sua auto-avaliação e pode ser solicitado a avaliar o seu Orientador de Estudo e Coordenador Local. Além do preenchimento dos dados cadastrais você deve avaliar o curso. [...] Todos terão acesso a estas informações e serão utilizadas pela Instituição formadora para identificar os aspectos que necessitam de melhoria durante a execução do curso de formação (BRASIL, 2013, p. 4).

Os professores alfabetizadores e orientadores de estudos passaram a ter acesso à utilização da plataforma em 2013, e nela inseriam seus relatórios de trabalho solicitados na formação, além de outras atividades, conforme pode ser observado nesta fala: “[...] Então, ah... desde o início do programa, todos os anos teve o SIMEC, que era um sistema de monitoramento. Lá... todos os orientadores tinham que, mensalmente, validar as bolsas através de... 100 por cento de presença e... entrega de trabalhos, relatórios e... atividades práticas realizadas [...]" (M1-E1Entrevista realizada em 10/01/2018). 
Desta forma, para a garantia dos benefícios todos os envolvidos tinham ações que deveriam ser previamente cumpridas:

Todos precisam dar conta das suas tarefas de acordo com os prazos estabelecidos pelo próprio MEC. A plataforma é 'alimentada' através do resultado dos relatos dos professores alfabetizadores e seus orientadores de estudo e dos resultados das avaliações externas aplicadas nas escolas dos professores participantes (RIBEIRO; LUCENA; ABREU, 2018, p. 204).

O SIMEC, então, direcionava os cursistas a cumprir uma avaliação própria no sistema, conforme o relato nas entrevistas: “[...] tinha acompanhamento acontecia através de uma plataforma on-line, o SIMEC, que era uma forma de monitorar frequência, e também acho que tinha uma área para avaliação, isso a orientadora poderá te informar melhor, né" [sic] (M2-E1-Entrevista realizada em 30/06/2018). O monitoramento das ações do PNAIC, via SIMEC, favoreceu a operacionalização e gestão do programa pelo MEC:

Em se tratando especificamente do monitoramento das ações desenvolvidas e sugeridas pelo PNAIC, o SISPACTO foi implantado pelo MEC em forma de site. O SIMEC é um portal operacional e de gestão do MEC, que trata do orçamento e das propostas on-line, preparação para convênios, e para receber assistência técnica e financeira do Governo Federal na área da educação. Pelo SIMEC, cada ente federado pode fazer o diagnóstico de sua situação e propor ações para superar as dificuldades ou para melhorar o desempenho de sua rede. Do ponto de vista do funcionamento do portal, para ter acesso ao sistema basta acessar a página da internet do SIMEC. O sistema é composto por módulos desenhados com a intenção de facilitar a sua utilização pelo usuário. Os módulos se dividem de acordo com 
os programas de políticas públicas em vigor, criadas pelo governo federal (RIBEIRO; LUCENA; ABREU, 2018, p. 203).

Para os referidos autores, a avaliação, assim, acaba se distanciando dos contextos nos quais os sujeitos concretos vivem no cotidiano das escolas e das salas de aula, seus conflitos pessoais, profissionais, sociais inerentes a uma prática cuja função deveria ter o propósito da melhoria da condição humana, no que diz respeito ao processo de ensino-aprendizagem (RIBEIRO; LUCENA; ABREU, 2018).

"[...] no sistema avaliava coordenador, alfabetizador, tinha esse espaço. Tinham também, daí tínhamos uma avaliação, sim, que tinha que ter até um certo percentual, até 70 por cento, porque se não nem recebia bolsa, tinha que ter a frequência, tinha que ter a apresentação dos trabalhos, nós também tínhamos que responder, nós... enquanto professor, até o orientador, coordenador, todos tínhamos que responder diretamente num portal pro MEC, do SIMEC, lá no portal direto do SIMEC. E... se não atingisse nem recebia bolsa, era cortada a bolsa." [sic] (M3-E1-Entrevista realizada em 08/10/2018).

Também, nesta plataforma havia um espaço para a avaliação dos orientadores locais, orientadores de estudos, todos os envolvidos no programa.

[...] professor alfabetizador, orientador de estudo, formador, supervisor, coordenador local, coordenador geral e coordenadores adjuntos, precisaram compreender e atuar no processo avaliativo de todos os perfis contidos no sistema SIMEC e as avaliações implicam no recebimento das bolsas atreladas ao programa (BRASIL, 2014a, p. 2).

Para dar conta da amplitude do programa, seria necessária uma forma de gestão e monitoramento de todos os envolvidos. Este programa tratava de uma importante ferramenta tecnológica que proporcionava as 
ações do Pacto, agilidade, transparência e reelaboração de estratégias, caso fosse necessário (BRASIL, 2014a).

Nele, professores, orientadores inseriam fotos e relatos sobre suas práticas, bem como as sequências didáticas, que eram uma prática ensinada para as alfabetizadoras. Sobre esse processo de avaliação via sistema, Ribeiro, Lucena e Abreu dizem não ter certeza da sua contribuição na formação do professor.

Em meio a esse emaranhado de dados, resultados e informações, uma questão se coloca. Esses resultados, por serem avaliados por mecanismos externos, nem sempre possibilitam o envolvimento dos professores e orientadores de estudos que necessariamente são alvo do acompanhamento do programa, o maior desafio que se depreende da análise do funcionamento do programa está, entre outras coisas, no fato do acompanhamento ser feito predominantemente por meio virtual. Embora se pretenda o cruzamento dos dados, não se pode ter a garantia de que as respostas dadas pelos envolvidos reflitam de fato suas concepções e práticas. Outro ponto diz respeito ao fato de que ao utilizar-se das avaliações externas e seus resultados como indicador de efetividade, o monitoramento deixa de contemplar questões dos professores e seus contextos de ação (RIBEIRO; LUCENA; ABREU, 2018, p. 203).

Se as avaliações externas não asseguram, necessariamente, que os resultados reflitam a realidade e as redes se restringindo às avaliações realizadas pelos orientadores de estudos e coordenadores locais, ambos envolvidos diretamente com a formação, pode-se inferir que os municípios não fizeram uma avaliação do programa de formação de professores alfabetizadores para além daquilo que fora exigido pela Coordenação de Aperfeiçoamento de Pessoal de Nível Superior (CAPES) por ocasião da assinatura do convênio. 


\section{Considerações finais}

O PNAIC, com início no ano de 2012, é umas das políticas públicas de alfabetização implantadas no Brasil nas últimas décadas e vinculadas àquelas que dispõem sobre alfabetizar todas as crianças até os 08 anos de idade. Neste programa com ações direcionadas a partir de quatro eixos de atuação, o primeiro tem como foco a formação continuada para professores alfabetizadores e orientadores de estudos das escolas públicas do país. Articulados a este estão os demais eixos que tratam de materiais didáticos, tecnologias e literatura educacionais; avaliação no nível da alfabetização; e gestão, controle e mobilização social.

A formação continuada do professor alfabetizador no PNAIC foi anunciada como uma estratégia para a melhoria na qualidade da educação e elevação dos índices de alfabetização dos sistemas de ensino, sendo realizada em parceria com as universidades públicas do país, que assumiram a função de coordenação-geral e adjunta no processo de formação. Seguiu o modelo de multiplicadores, onde cada grupo participante tinha um papel na formação, desde a coordenação-geral e adjunta, coordenação de polo, até a coordenação local e orientadores de estudos, estes atuando em âmbito municipal na formação do professor alfabetizador.

Ao observar as falas dos orientadores de estudo e dos coordenadores locais, pode-se perceber que a prática do professor alfabetizador foi um elemento importante no processo de formação. A partir dela é que o processo de estudos e reflexões ocorria, dando certo protagonismo ao professor alfabetizador nesse seu processo de formação. Evidentemente que isso não torna este modelo de multiplicadores a melhor forma de realizar a formação continuada. Mas, num país com a dimensão territorial do Brasil, somada às suas diferenças sociais e culturais, foi um caminho encontrado pelo Estado para chegar a todos os professores alfabetizadores. 
Os resultados alcançados com a pesquisa evidenciam que na região da AMUREL a formação ofertada pelo PNAIC foi significativa para os professores que dela participaram, haja vista afirmarem que nesta formação tiveram a possibilidade de mudar seu fazer e se redescobrir enquanto ser social e profissional, dando novo direcionamento à prática pedagógica desenvolvida em sala de aula nas classes de alfabetização.

No que se refere à avaliação da formação de professores pelo PNAIC, os resultados mostraram que não houve avaliação específica ou acompanhamento por parte dos gestores municipais ou estaduais, sendo esta função realizada pelo orientador de estudos e/ou coordenador local, parte das suas atribuições estabelecidas nos documentos do Pacto referentes à formação.

Não se constatou, por parte dos municípios, movimentos ou ações no sentido de fazer com que os conhecimentos adquiridos pelos professores alfabetizadores a partir da formação obtida no PNAIC fossem efetivados, na prática, como uma política de alfabetização para os municípios. Enquanto realizava o curso, o professor colocava os novos conhecimentos em prática em sua sala de aula, haja vista ser parte da formação a reflexão sobre a prática. No entanto, após conclusão do curso a opção de continuar ou não com a concepção de alfabetização trabalhada na formação ficou sob responsabilidade e decisão de cada participante.

Ainda assim, acredita-se ter sido um programa de formação que certamente mudou muitas práticas de alfabetização nas escolas e que permitiu aos participantes incorporarem novos conhecimentos e alterarem sou modo de conceber e desenvolver seu fazer cotidiano.

Mesmo tendo clareza dos limites desse programa de formação continuada, políticas públicas como esta proposta no PNAIC devem ser transformadas em políticas permanentes, dada sua importância e necessidade, quando se pensa em melhorar a qualidade da educação no país.

O Pacto, assim como os outros programas que o antecederam, foi muito importante no que tange à busca pela prática da reflexão e 
investigação do fazer docente, redefinindo sua metodologia e visão do processo de alfabetização. Políticas educacionais permanentes são fundamentais, para que haja a mobilização dos diversos segmentos sociais para soluções da erradicação do analfabetismo no país, criando condições efetivas para a continuidade dos estudos para todas as crianças.

\section{Referências}

ALFERES, M. A.; MAINARDES, J. O Pacto Nacional pela Alfabetização na Idade Certa em ação: revisão de literatura. Ensaio: aval. pol. públ. Educ., Rio de Janeiro, v.27, n.102, p. 47-68, jan./mar. 2019.

AMUREL. Associação de Municípios da Região de Laguna. Disponível em: <amurel.org.br>. Acesso em: 10 jan. 2019.

BRASIL. Lei $n^{o}$ 11.274, de 6 de fevereiro de 2006. Disponível em: <http://www2.camara.leg.br/legin/fed/lei/2006/lei-11274-6-fevereiro-2006-540875publicacaooriginal-42341-pl.html>. Acesso em: 10 jan. 2019.

- Ministério da Educação. Pacto Nacional pela alfabetização na idade certa. Toda criança alfabetizada até os oito anos. Documento de Orientação das Ações de Formação. Brasília: Ministério da Educação, 2015.

Portaria $n^{o}$ 867, de 4 de julho de 2012. Disponível em: $<\mathrm{http} / / / w w w . l e x . c o m . b r / l e g i s \_23490618$ PORTARIA_N_867_DE_4_DE_JULHO_D E_2012.aspx>. Acesso em: 10 jan. 2019.

. Secretaria de Educação Básica. Diretoria de Apoio à Gestão Educacional. Pacto nacional pela alfabetização na idade certa: Apresentação / Ministério da Educação, Secretaria de Educação Básica, Diretoria de Apoio à Gestão Educacional. - Brasília: MEC, SEB, 2014.

Ministério da Educação. Pacto pela Idade Certa é desafio e prioridade, afirma ministro. 2013. Disponível em: <http://portal.mec.gov.br/ultimasnoticias/211-218175739/18572-pacto-pela-idade-certa-e-desafio-e-prioridadeafirma-o-ministro>. Acesso em: 11 fev. 2019.

Ministério da Educação. SIMEC. Disponível em: $<$ http://portal.mec.gov.br/secretaria-de-regulacao-e-supervisao-da-educacaosuperior-seres/114-conhecaomec-1447013193/sistemas-do-mec-88168494/143simec $>$. Acesso em: 10 ago. 2018.

FREITAS, H.C.L. Formação de professores no Brasil: 10 anos de embate entre projetos de formação. Educação \& Sociedade, Campinas, v.23, n.80, p.137-16, 2002. 
HOBOLD, M. S.; SILVA, V. M. Percepções de docentes sobre as ações de formação continuada, promovidas pela rede municipal de ensino. In: X ANPED SUL. Anais [...] Florianópolis, outubro de 2014.

LIBÂNEO, J. C.. Organização e gestão da escola: teoria e prática. $5^{\mathrm{a}}$ ed. São Paulo: Alternativa, 2004.

MICARELLO, H. A. L. S. A avaliação no âmbito do Pacto Nacional pela Alfabetização na Idade Certa. Revista Educação em Foco (UFJF), [s.l.], p. 63-79, 24 maio 2015. http://dx.doi.org/10.22195/2447-5246v0n020152957.

RIBEIRO, A. E. A.; LUCENA, M. C. D.; ABREU, A. C. S. O Pacto Nacional pela Alfabetização na Idade Certa (PNAIC) e suas ações: o monitoramento como desafio. Momento: diálogos em educação, v. 27, n. 2, p. 188-206, maio/ago. 2018.

SHIROMA, E. O.; MORAES, M. C. M. de; EVANGELISTA, O. Política educacional. Rio de Janeiro: DP\&A, 2002.

SIMEC/SISPACTO. SIMEC $t d i$ Avaliação. Disponível em: <https://simec.pro.br/simec-dti-avaliacao/>. Acesso em: 23 nov. 2018. 